Ministry of Education Iraqi Directorate of Education Baghdad Karkh III

First Conference Department of Preparation and Training Division of Research and Studies

وزارة التربية العراقية مديرية تربية بغداد الكرخ الثالثة الهؤتمر الاول قسم الاعداد والتدريب شعبة البحوث والدراسات

\title{
PHonetcs
}

\author{
Amin Jabbar Ailwan Alsaedy \\ Directorate of Baghdad Education Karkh III, Ministry of Education, Baghdad, Iraq
}

\author{
333hom@gmail.com
}

\begin{abstract}
In this manuscript, I tried to prove that there is a relationship a many sound , phonetic semantic and the origin of the language is endowment from Allah almighty, so language has the in imitability of the Quran and the phonetic semantic using verses of the Quran . of which is attributed to the divine self with the angles and then to Adam's sons. This language is taught by Allah almighty to his creatures in a high level in sound phonetic semantic and eloquence He taught something that is at the top of the ranks of science and not as the mechanism of some of our scientists to. And the man is the one who puts them. Then I addressed the qualities of the voice and dividing them according to scientists for its semantic relationship to the phonetic semantic for letters.
\end{abstract}

Keywords: phonetics, sound, sound in language.

\section{علم الصوت اللغوي}

\author{
امنة جبار علوان الساعدي \\ وزارة التربية، مديرية تربية بغداد الكرخ الثالثة، بغداد، العراق \\ 333hom@gmail.com
}

المستخلص حاولتُ في بحثي هذا اثبات وجود علاقة بين الصوت ودلالته وبين نشأة اللغة ، وأنّ اللغة وقفية من الله تعالى ومن هذا الأمر تمتلك الإعجاز والدلالة الصوتية مستنده بآيات من القرآن الكريم منها

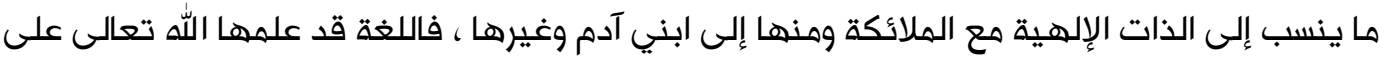

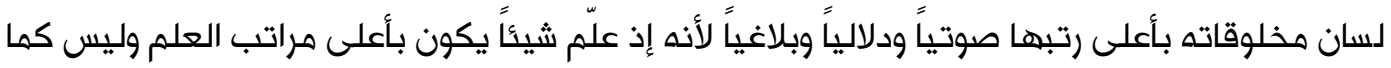

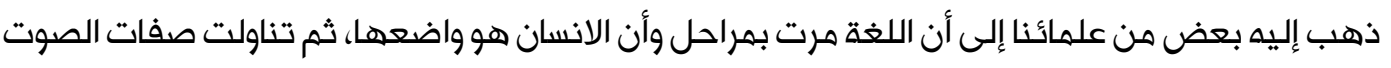
وتقسيمه عند علماء الصوت ، لعلاقتها بالدلالة الصوتية للحروف. الكلمات الدالة: الصف الصوت اللغوي، علم الصوت، الصوت في اللغة. 
الحمد لله رب العالمين والصلاة والسلام على أشرف المرسلين محمد وعلى إله الطيبين الطاهرين وأصحابه الهنتجبين وبعد......

فإن اللغة العربية منذ القدم وما زالت تحظى بالاهتمام والدراسة لأنَّها لغة القرآن الكريم، وكانت الدراسة تصب اهتمامها على علم (النحو والصرف) ثم تفرعت عنهما البلاغة وغيرها من العلوم، أما علم الصوت فهو علم حظي باهتمام تنطوي صفحاته في كتب اللغة دون أن يكون علماً مستقلاً....، ثم ما لبث أنْ تطور علي يد ابن جنيَّ (ت392)، وفي العصر الحديث لقي علم الصوت اهتماماً عند علماء اللغة العربية كعلم له أصوله وفروعه.

ونحن في صدد هذا البحث نحاول أن نتطرق الى موضع لطالما كانَ محطَّ جدلٍ وخلاف بين العلماء محاولين أن نقدم بذرةً من الحقائق العلمية عن علم الصوت اللغوي وقسمنا هذا البحث إلى ثلاثة محاور، الهحور الاول:(جدلية الدلالة الصوتية) يبين فيه الجدلية بين العلماء في ارتباط الصوت بالدلالة، ونعرض فيه بعض آراء العلماء بين مؤيد ورافض لهذه العلاقة ، والهحور الثاني :(نشأة اللغة العربية

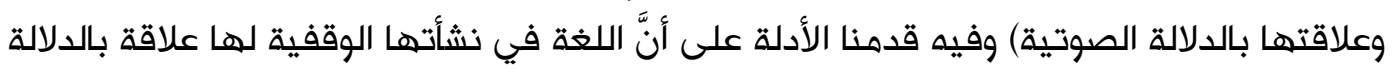
الصوتية ، والمحور الثالث:(الحروف وصفاتها) تناول فيه دراسة مفهوم الصوت عند القدماء والمحدثين، وقد قدمنا فيه دراسة صفات الأصوات قبل المخارج لما اقتضته منهجية البحث ونسأل الله أن يوفقنا في تقديم هذا البحث.

\section{• مشكلة البحث}

علم الصوت من العلوم المهمة، فقد احتل مكاناً مهمهاً وهميزاً من بين علوم اللغة العربية اليوم، ورغم أهمية هذا العلم لا تزال مكتبتنا العربية فقيرة بمؤلفات علم الصوت رغم ازدهارها بعلم النحو، والصرف، والبلاغة ... وخاصة إذا ما قورنت بالتطور الذي حققه علماء الغرب في هذا الهجال، ولا تزال أقلام العلم تتخبط في هذا الميدان العلمي المهم ... فأراء العلماء بين أخذ ورد وأصبح الكلام عن الدلالة الصوتية أمر يهمشهُ كثير من العلماء فقد عد أغلبهم أن الادلة التي تثبتٍ حقيقة وجوده قليله.

\section{•}

تأتي أهمية البحث في إن معرفة الدلالة وربطها بالصوت يثثري المعرفة اللغوية من حيث فهم سياق الكلام ... بل إن هذا العلم كما هو متعارف عليه قد وضِع منذ القدم من أجل خدمة القرآن الكريم، لمعرفة معناه اثناء تلاوته على أذهان الناس، وإحلال صوت مكان صوت أخر له يؤدي الى تغير في المعنى، وبالتالي معرفة (الدلالة الصوتية) تساعد على معرفة علمية وهي استخدام الصوت بشكل

$$
\text { سليم نطقاً وفكراًً... }
$$

الساعدي، امنة جبار علوان. (2019). علم الصوت اللغوي. Journal Port Science Research، 2(3) ، 479-463. 
1) نثبت حقيقة ان علم الصوت الدلالي نشأ في أحضان عربية قبل الغرب، وهذه ميزة علمية تحتسب لعلمائنا الاوائل. 2) إثبات أن نشأة اللغة وقفية من الله تعالى وبالتالي فإنها وحي اعجازي من الله على لسان البشرية، وإعجازها يتمثل في الصوت، والتركيب، والجمل.

3) الإعجاز الصوتي موجود في القرآن الكريم خصوصاً وفي اللغة عموماً، مثال النصوص الشعرية والمعلقات وخطب الرسول والائمة.

$$
\text { • حدود البحث }
$$

وضع نتائج تؤكد ارتباط الصوت بالدلالة وتأثير هذا العلم باللغة تأثيراً هباشراً.

\section{•}

1) الدلالة: العلم الذي يدرس المعنى أو دراسة المعنى.

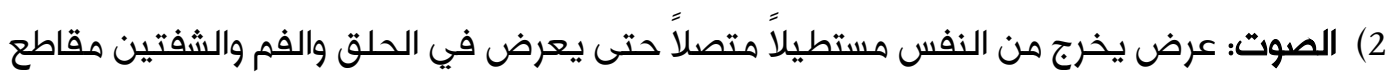
تثنيه عن اهتداده واستطالته.

3) اللغة: مجموعة من التقاليد الضرورية التي تبناها الهجتمع ما ليساعد أفراده على ممارسة هذه

الملكة.

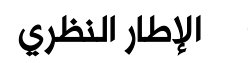

دراسة ما قدهم القدماء والتي تعدّ البذرة الاولى في هذا العلم ثم نجعل حقة يقة نشأة اللغة والتي تُذكر

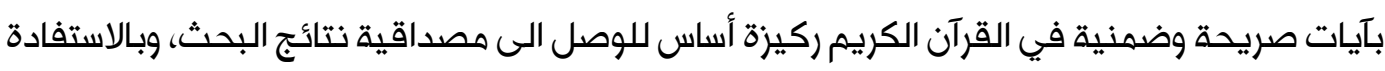
أيضاً من دراسة الغرب الذين قدموا لنا حقائق علمية أصبحت مناراً لهذا العلم.

$$
\begin{aligned}
& \text { الدراسات السابقة } \\
& \text { 1) العين للخليل الفراهيدي ت (170هـ) }
\end{aligned}
$$

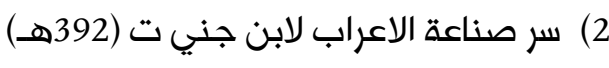

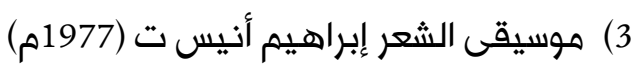

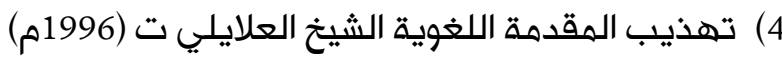

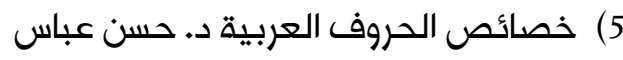


لقد وقف العلماء القدماء والمحدثون بين مؤيّد لوجود علاقة طبيعية بين الدال والمدلول وآخر رافض مض هذه العلاقة ويرى إنّ هذه العلاقة اعتباطية، وتعرّف الدلالة "ذلك الفرع الذي يدرس الشروط الواجب توافرها في الرمز حتى يكون قادراً على حمل الهعنى [1]، واشار الفراهيدي بقوله: " صَرَّالجُنُب صرياً وصرصر الأخطبُ صرصرة فكأنهم توهمهوا في صوت الجندب مداًً توهموا] في صوت الاخطب ترجيعاً "....." [2] أهّا ابن جني فعقد في كتابه (الخصائص) باباً " في تصاقب الالفاظ لتصاقُب المعاني"، وباباً " في إمساس الألفاظ اشباه المعاني" ، وأكد على مقابلة الالفاظ بما يشاكل أصواتها ، ومما جاء في بـ بابي كلاهه ..." فأمّأ مقابلة الألفاظ بما يشكل أصواتها من الاحداث فباب عظيم واسع ، وهنهج متلئب عند عارهيه مأموم ، وذلك أنّهم كثيراً ما يجعلون أصوات الحروف على سمت الاصوات المعبّر عنها، فيعدلّونها ويحتذون عليها، و ذلك أكثر مما نقدره واضعاف ما نستشعره، ومن ذلك قولهم اهم : خَضم، وقضم ، فالخضم لأكلّ الرَّطب ... والقضم للصُّب اليابس .... [3] وهما يُذكرُ له في هذا الصدد ايضاً

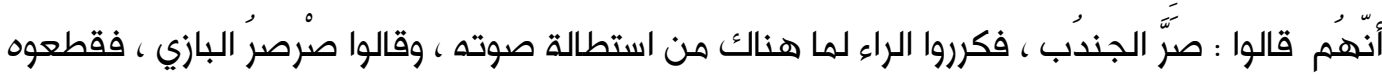

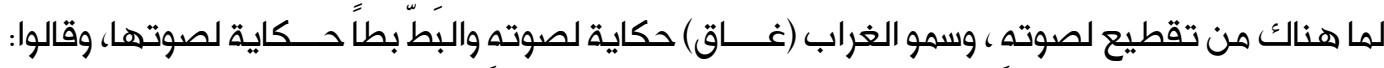

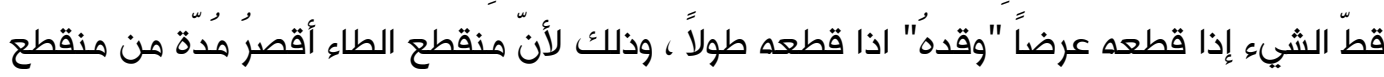

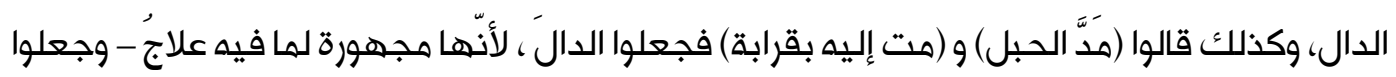
التاء - لأنها مهموسة لما لا علاج له " (ابن جني ، الجزء الاول ، ص 165 ، 166) • ورغم ان ابن جني لم

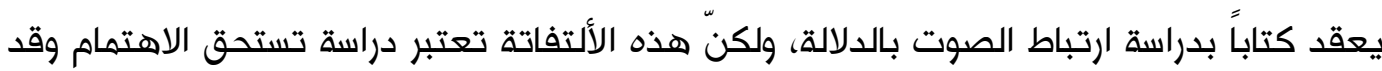
حضيت بالقبول عند الباحثين، وفي القرن التاسع عشر ظهر تأثُّ علماء اللغة العرب المحدثين بعلماء آناء الغرب مستفيدين من تجارب العرب الاوائل، فمنهم من يرى أَنّ العلاقة بين الصوت والدلالة قائمة والآخر ينفي هذه العلاقة الدلالية الصوتية ....

ومن العلماء المحدثين الذي يؤيد وجود هذه العلاقة الشيخ (العلايلي) الذي يرى .... أن لكل حرف ماف معنى ويقف عند الصوت المنعزل، فيقول: "الهمزة تدل على الجوفية، والباء تدل على بلوغ المعنى في الشيء بلوغاً تاماً والجيم تدل على العظم مطلقاً والخاء على المطاوعة والانتشار والذال على التفرد والراء على الملكة وشيوع الوصف والسين على السعة والبسطة والشين على التفشي ... " (العلايلي، 1985، ص 63) [4]، ومن اللذين ساروا على هذا النهج د. حسن عباس (عباس، 1998، ص53) [5]. وأيضاً ما يذكر بهذا الصدد "... إنّ كل حرف يختص بمعنى من المعاني دون غيره وهو سر من اسرار العربية التي قلّ من تنبه اليها ...، ومن خصائص حرف الحاء مثلاً السعة والانبساط نحو البراح والابداح 
والابطح وحرف الميم يدل على القطع والاستئصال والكسر نحو جسم حطم حلقم وحزم وخضم ...".

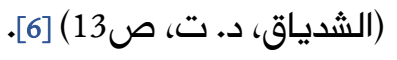

ولكن هناك علماء احتجوا على هذه العلاقة الصوتية الدلالية ومنهم محمود حجازي ومن جملة ما قاله: " فليس هناك أيّ علاقة بين كلمة حصان ومكونات جسم الحصان ...، وإذا كانت هناك ثمة علاقة بين اللفظ والمدلول، فإنها لا تعدوا على كونها اصطلاحية عرفية ..." (الحجازي، د. ت، ص11) [7]. وغيره من علماء اللغة الذين رفضوا فكرة وجود علاقة بين الصوت والدلالة، ولم نصل الى وقتنا هذا إلى رأي قاطع ينهي الخلاف العلمي. ثم نلتفت الى علماء الغرب اللذين لا تخفى جهودهم المبذولة في التجارب الصوتية، والتي وصفها ابراهيم انيس (د. ت) في كتابه الاصوات اللغوية بإنها كالسحر ، لمّا امتازت بها من الدقة العلمية ، وموقفهم لا يكاد يختلف عن العلماء العرب وهو بين مؤيدٍ ومعارضٍٍ لعلاقة الصوت بالدلالة ، ومن اللذين نادوا بوجود العلاقة الصوتية الدلالية هو همبلت الذي قِال في مقِال نشره ذكرّ فيه "... إنّ اللغات بوجه عام تؤثر التعبير عن الاشياء بوساطة ألفاظ أثرها

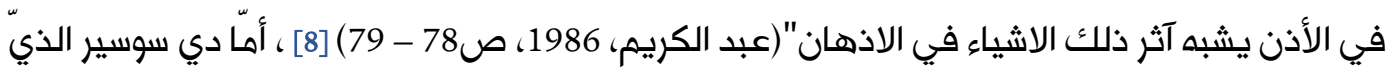
يعدّ مؤسس البنية اللغوية لمّا لآرائه من صدى واسع بين علماء الصوت فرأينا أن نلخص من آرائه ما

1) " إن الدلالة اللغوية لا تجمع بين شيء واسم، وإنما تجمع بين مفهوم وصورة سمعية، وهذه الاخيرة ليست هي الصوت المادي، اي شيئًا فيزيائياً خالصاً بل هي بصمة نفسية لهذا الصوت " (بافو وسرفاتي ، 2012 ، ص 118) [9]، إذن الدلالة اللغوية كل يتكون من تصور وصورة صوتية ، ولا يعني بالصورة السمعية الجانب الفيزيائي للصوت بل نقصد الاثر السيكلوجي (النفسي) لهذا الصوت. 2) اما دي سويسر (1985) فقد أطلق على المفهوم مصطلح المدلول وأطلق على الصورة السمعية مصطلح الدال، ونقصد بالصورة السمعية (الصوت) و(المفهوم) الشيء المادي، واعتبر العلماء هذه التسميات كالاتي (الدليل - الدال - المدلول) يعتبر هذا الثالوث كما وصفهُ البعض من أهم

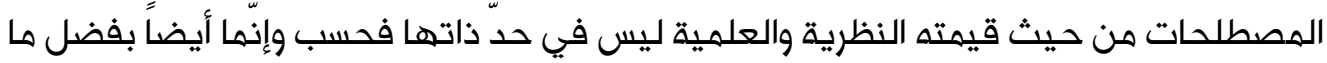
تم له من امتداد الى مجالات آخرى غير مجال الألسنية هي من مشهولات ما أصبح يسهى (أثر دي

$$
\text { سويسر لعلم الدلائل). }
$$

3) وقد وصف سويسر (1985) الدليل اللغوي بأنه كيان واحد لا يتجزأ والتفت الى أنّ الدال ليس مبرراً دائماً ولكنّ الكلمات التي توحي بمعناها ليست عناصر حيوية (عضوية) في النظام اللغوي ، ثم إن عددها أقل بكثير مما يعتقد ... فضلاً عن أن اختيارها يكون عادة بصورة اعتباطية ، لأنها محاولات تقريبية تعتمد على العرف ايضاً نستنج أنّ دي سويسر يرى أن لا علاقة صوتيه بين

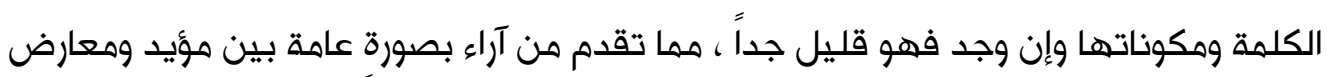


للعلاقة الصوتية والدلالية الظاهر لي أن الرأي الذي يرى أنَّ هناك علاقة بين الصوت والدلالة هو أقرب للواقع الصوتي والدليل على ذلك أن الاصوات لكل منها مخرجٍٍ وصفهُ تختلف كل الاختلاف عن بعضها بل لكل صفة صدى معنوي لا يخفى فمن غير المعقول أن تأتي هذه الصفات الصوتية تكون اعتباطية أو موضعه من قبل جماعة أو نتاج انساني كما يقول البعض أو ساعدت الطبيعة على وضع هذه الأصوات وسنعرض في المحور القادم أدلة تساعدنا للوصول الى ما هو ترجحهُ الأدلة العلمية في البحث ان شاء الله [10].

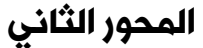 \\ نشأة اللغة وعلاقتها بالدلالة الصوتية}

اللغة عرفها دي سويسر: " انتاج جماعي لملكة اللسان ومجموعة من التقاليد الضرورية التي تبناها مجتمع ما ليساعد افراده على ممارسة هذه المَلكة " (سويسر ، 1985 ، ص 28).

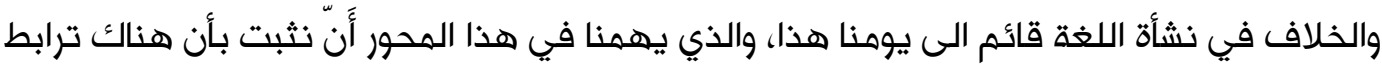
بين نشأة اللغة والدلالة الصوتية للحرف ... ولنعرض هذه الآراء وكما يلي: اشار عباس (1998) ان من العلماء من يرى إن اللغة وقفية من الله تعالى. من العلماء الذين اعتبروا ان الحرف العربي مرّ بهراحل تطورّ منهم الشيخ العلايلي وابراهيم أنيس (د.ت) في كتابه الاصوات اللغوية، وحسن عباس الذي يرى أنّ الحرف العربي مرّ بمراحل ثلاث "الهيجانية والايمائية والايحائية ... فالهيجانية أقل تطوراً من الايمائية ، وهذا أقل تطوراً التهن من

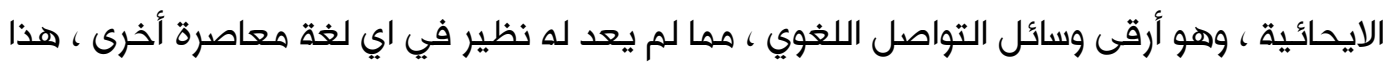
يعني ان الحروف العربية تنتمي بالضرورة الى مراحل حياتية ثلاث متفاوته في التطور والرقي ..." (عباس ، 1998، ص9) ... ثم يكمل مسيرته الاستقصائية العلمية بقوله ... " الإنسان العربي والحرف العربي قد تعايشا في الجزيرة العربية خلال ثلاث مراحل حياتيه هي : الغابية وقد بدأت مع بداية العصر الجليدي الأخير منذ الألف (100) ق.م واستمرت حتى نهايته في الألف (14 -12 ) ق •م وقد ورثنا عنها يقيناً أصول أحرف (الهمزة - 1 - و - ي) ثم تلتها الأصول الزراعية حتى الألف ق.م وقد ورثنا

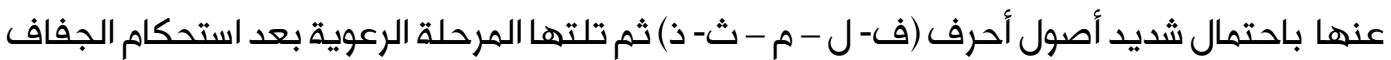
في الجزيرة العربية واستمرت حتى العصور الجاهلية وفجر الاسلام وقد ورثنا عنها بقية الحروف" (عباس، 1998، ص10) وبكل احترام نقول إنّ هذا الرأي وان خضع إلى جهود علمية قد أكدت بين طياتها الدقة العلمية فهو أجاد في دراسته الحرف واثبات العلاقة بين الصوت والدلالة ، ولكنّ لا يخفى على القارئ كأنهُ قد سارَ على نهج الغربيين في تصنيف تكوين الأصوات عبر مراحل التاريخ ..... ونحن بهذا الصدد سنعرض أدلة من القرآن الكريم لنؤكد إن نشأة اللغة وقف مِ من الله تعالى وبالتالي أنهُ تُعالى قد علّمِ اللغة على لسان آدم (ع) بأدق تفاصيلها، من حروف وتراكيب وجمل ... الخ، وتصبح اللغة في حدِّ ذاتها إعجاز إلهي بكل معالهها، بل الظاهر لي أن اللغة قد بدأت بأعلى مستوياتها الساعدي، امنة جبار علوان. (2019). علهم الصوت اللغوي. Journal Port Science Research، 2(3) ، 
الصوتية والدلالية والبلاغية ... الخ، ثم بدأت تفقد سحرها الصوتي والدلالي والبلاغي بمرور الزمن بسبب اختلاط الألسن وغيرها والله أعلم .... ونعرض بعض الآيات الكريمة التي نعدها دليلاً على إن اللغة وقفٌ من الله وبالتالي اثبات وجود العلاقة الصوتية الدلالية والتي تضمنت الحوار بين الذات الإلهية المقدسة وبين مخلوقاته....

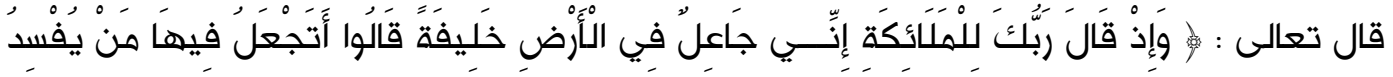

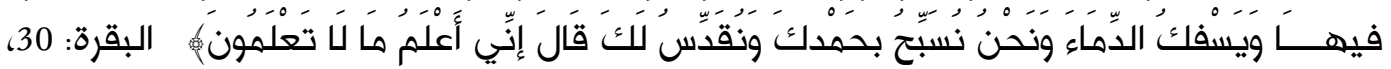

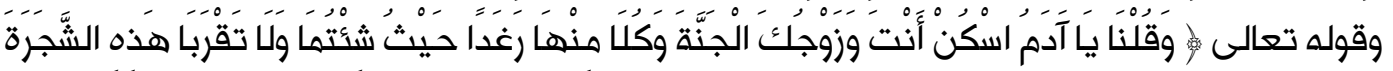

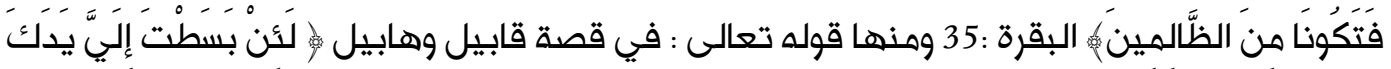

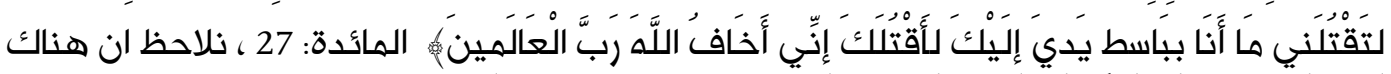

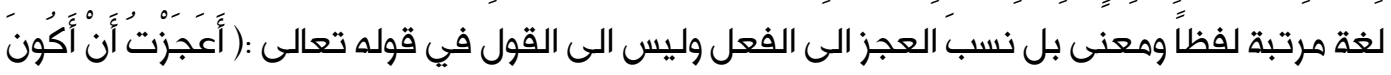
مَْلَ هَذَا الْغرَاب) سورة المائدة الاية31، وتتصدر الآية الكريمة لفظة (القول) وهو عند علماء اللغة

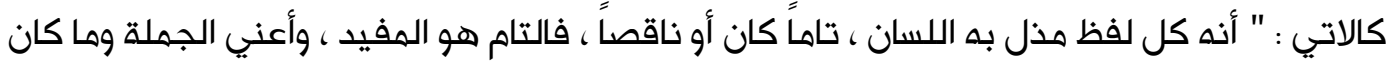
في معناها ، من نحو صه ، وابه ، والناقص ما كان بصدد ذلك. " والفرق بين الكلام والقول إجماع الناس أن يقولوا: القرآن كلام الله، ولا يقال: القرآن قول الله، وذلك همالك أن هذا موضع ضيق متحجر، ولا يمكن تحريفه ولايسوغ تبديل شيء من حروفه فعبر لذلك عنه بالكلام الذي لا يكون إلا اصواتاً تامه مفيده وعدل به عن القول الذي يكون اصواتاً غير مفيدة، واراء معتقدة ..." (ابن جني، 1952، الجزء الاول، ص18)، ونحن لسنا في صدد معنى (قال أو - كلّم) وانّما الذي يهمنا فيها عرضنا اثبات وجود اللغة مرتبة منزله من اللّه تعالى.

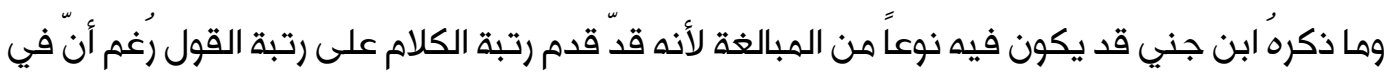
القرآن الكريم تُنسب كلمة (القول) إلى الله تعالى وإلى الملائكة وإلى الانبياء وفي نفس الوقت تنسب الى الكافرين والشياطين. فالظاهر لي أن بعدَكلمة القول يأتي بمنزلة الخبر يحتمل الصدق والكذب والتفاعل بين اكثر من طرف

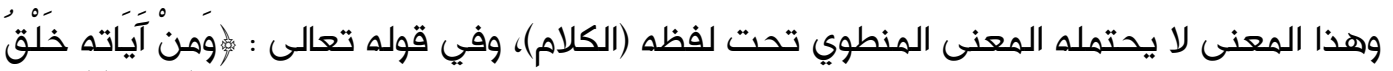

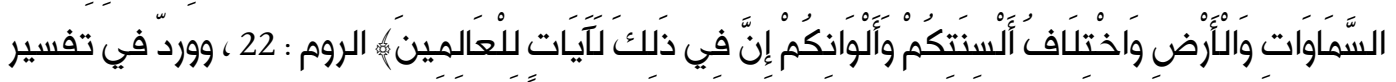
كلمة (السنتكم) (لغاتكم) او (اصواتكم) وقد اشار الشيخ الطباطبائي (1417هـ ) [11] الى ان اصواتكم الراجح في معناها (لغاتكم)، والظاهر لي بما ان الآية تتصدرها كلمة (ومن آياته...) فهي وقفية من الله، فهل تبقى بعد هذه الادلة من شك في نشأة اللغة او من يعارض العلاقة الصوتية الدلالية 


\section{المحور الثالث}

\section{أولاً: مفهوم الصوت}

لغةً: " الصوت:ُ الجرس .... وقد صات يَصَوت .... يصاتَ صوتاً، وآصاتَ، وصوَّت به، كله نادى .... " (ابن

$$
\text { منظور، 2009، الجزء الثامن، ص } 302 \text { مادة: صوت) [12]. }
$$

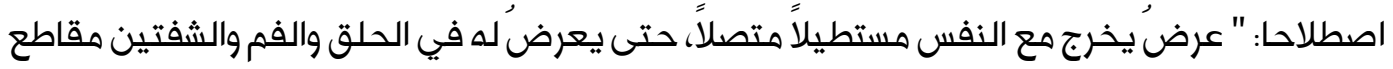
تثنيه عن امتداده واستطالته ... "(ابن جني، 1993، الجزء الاول، ص6) [13]، "والصوت ينتج من ذبذبات هصدرها الحنجرة" (انيس، د. ت، ص 9) [14]، وتعرف الحنجرة عند مالمبرج (1984) [15] في كتابه علم الاصوات " هي التي تنشئ الطاقة الصوتية الهستخدمة في الكلام... ". والدراسة العلمية "تؤكد أن انتاج الصوت: يتكون من موجات تنتقل عبر الهواء بسرعة تبلغ (1100 م) قدم في الثانية ، وعلى الاغلب فإن علماء الصوت يعزون ظاهرة الصوت الى الاوتار الصوتية وما يحصل فيها من تغير هو السبب الرئيسي في حصول الصوت والاوتار مسهى تعزوه الدقة فالوتران حقيقية الامر شفتان تأخذان شكلاً متماثلاً على يمين ويسار الخط الوسطى وتتكون من عضله درقية هرمية ، ونسيج مرن الرباط وفوق الوترين الصوتين الزائفين او ثنتي البطين وهاتان لا علاقة لهما بعملية

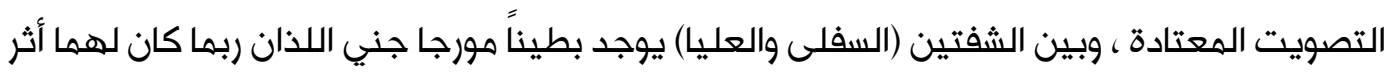
معين على النغمة الحنجرية. ويقرر علماء وظائف الأعضاء أن هذا الوتر لا يحدث اساساً عن طريق شّد الوترين الصوتين كما كان الاعتقاد في الماضي، بل عن طريق انكماش داخلي، ففي حالة الصوت ذي النوعية الخفيضة يكون الوتر الصوتي سميكاً أما في حالة الصوت ذي النوعية الحادة يكون الوتر الصوتي رقيقاً متخذاً شكل شريط تقريباً ... "(مالمبرج، 1994، ص60 - 61) [16]. والظاهر لي أنّ هذا الرأي بما يمتلكه من دقة علمية يقترب من التحليل العلمي للصوت بشكل أدقّ فالأوتار الصوتية ليست هي الوسيلة المؤثرة المباشرة في صفات الأصوات بل هي خاضعه لتغيرات دهات مختلفة بدءاً من تيار الهواء القادم من الرئتين، "فالازدياد في حجم الرئتين يتطلب دخول الهواء

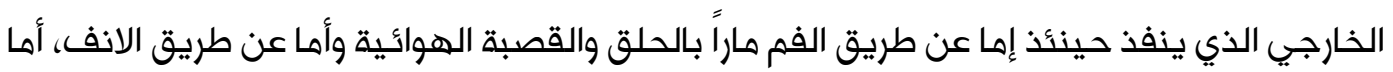
الزفيرُ فيتطلب رفع الحجاب الحاجز وخفض الضلوع مما ينتج عنه طرد جزء كبير من الهواء الموجود في الرئتين هذا الهواء المطرود بفعل حركة الزفير هو الذي يستعمل في الكلام ... "(مالمبرج، 1994،

مما تقدم من تحليل علمي رسم لنا صورة دقيقة إلا أن المعتمد عليه في علم الصوت هي تعاريف توارثت من القدماء بدءاً من الخليل مروراً بسيبويه وعمدَت على يد ابن جني كعلم له اصولهُ وفروعه وتردد صداها على لسان المحدثين وربما اضافوا بعض التغيرات البسيطة فالأوتار الصوتية تعتبر

$$
\text { الركيزة الاساس في تكون الصوت عند القدماء، واغلب المحدثين. }
$$

الساعدي، امنة جبار علوان. (2019). علم الصوت اللغوي. Journal Port Science Research، 2(3) ، 479-463. 
وقد قسم الدكتور غانم قدوري مستفيداً من علماء التجويد الاصوات الى قسمين اولاً- صفات مميزة ثانياً: الصفات محسنه الصفات المميزة "سميت بهذا الاسم لأن من شأنها التمييز بين الاصوات المتشاركة في المخرج الواحد،

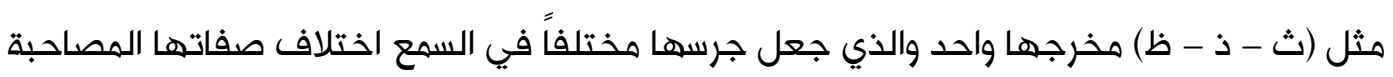
لها في تكون مخرجها الثاء مهموس، والذال مجهور، وصفة الجهر في الذال ميزته عن الثاء، والظاء مجهور مطبق، وصفه الاطباق فيه ميزته عن الذال، وهكذا وأهم الصفات المميزة: الجهر ويقابله الهمس والشدة وتقابلها الرخاوه، والاطباق ويقابله الانفتاح" (الحمد، 2004، صـانه هـ101) [17].

\section{الهجهور والمهموس}

والمجهور لغةً: " الجهر هو رفع الصوت، وجهره وأجهره فهو مجهور، إذا كان حاد الصوت، وجهر

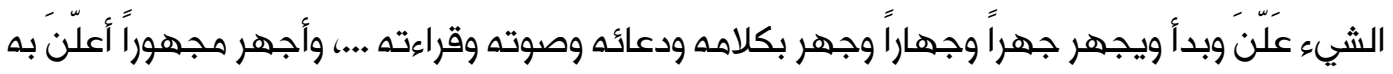

$$
\text { واظهره ... "(ابن منظور، 2009، الجزء الثالث، ص226 مادة: جهر). }
$$

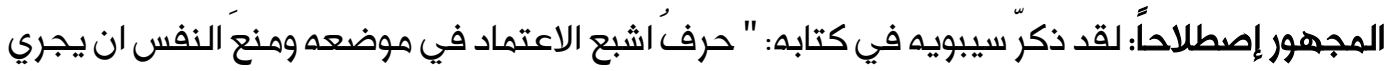
معه، حتى ينقضي الاعتماد عليه ويجري الصوت ... "(سيبويه، 1988، الجزء الرابع، ص434) [18]، وعند المحدثين : " الجهر هو اهتزاز الوترين الصوتيين عند النطق بالصوت ، فالصوت المجهور هو اهتزاز الوتران الصوتيان " (الصيغ ، 1998، ص 107) [19] واشار ايوب (1986) [20] انها تعرف بالأصوات الهمس لغةً: " الخفي من الصوت والوطء والأكل، وقد همسوا الكلام همساً ... ويقال اهمس وصه، أيّ امش خفياً واسكت ... الهمس الكلام الخفي لايكاد يفهم، وهو ما همس في الكلام ... " (ابن منظور، 2009، الجزء الخامس عشر، ص 92 مادة: همس).

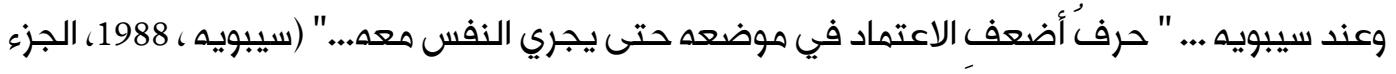
الرابع عشر ، ص 434) و عند الهحدثين : (الهمس عدم اهتزاز الوترين الصوتيين ، فالصوت الههموس هو الذي لا يهتز معه الوتران الصوتيان و لا يسهع لهما رنين حين النطق به"(ايوب ، 1968، ص 122) وذكر ابن جني انها تجمع بكلمة ستشحثك خصفه، وتعرف عند ايوب بالأصوات غير الحنجرية، مما تقدم فإنّ الجهود التي قدموها المحدثون في البحث الصوتي هي جهود مكملة للعلماء القدماء؛ ولكنّ تبقى الريادة للقدماء بهذا المجال العلمي، أمّا ما تقدم من تعريف ذكرهُ سيبوية (للمجهور

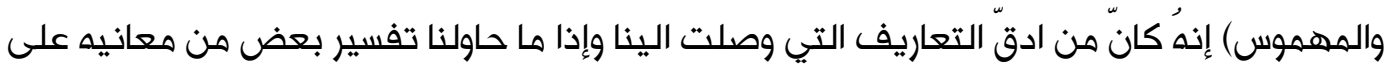
حرف ُأشبع الاعتماد في موضعه = قوة انضغاط الذفس في موضع خروج الصوت والذي يعرف بالمقطع دون اضطراب في مخرجه الناتج من ازدياد حجم الرئتين بسبب انحباس الهواء القليل. 
تتنوع طريقة اعتراض اعضاء النطق للنفس في مخرج الصوت، فيمكن أنّ يكون الاعتراض تاماً، وذلك

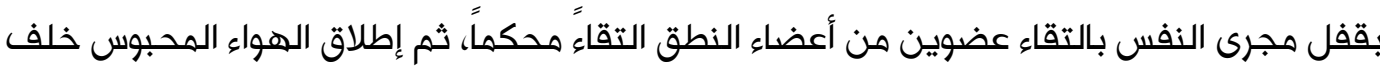
العضوين ويحدث ذلك في نطق صوت الباء مثلاً. ويمكن أن يكون الاعتراض في أدني درجاته، وذلك بأن تكون أعضاء النطق مفتوحة بقدر ما تسمح طبيعتها، ويكون ذلك في نطق صوت الفتحة والألف

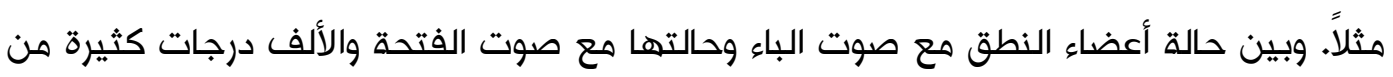
الانفتاح، وصور متعددة لاعتراض النفس في مواضع النطق، وتنوع الاصوات تبعاً لذلك التنوع في درجات الانفتاح وتعدد أشكال الاعتراض... وعلى هذا تُصنف أصوات العربية في التراث الصوتي العربي بناء على هذا الاساس على ثلاثة انواع

الأصوات الشديدة عند سيبوية: " الذي يمنع الصوت أن يجري فيه ، وهو الهمزة والقاف والكاف والجيم والطاء ، والتاء والدال والباء (سيبويه ، 1988 ، الجزء الرابع ، ص434) " وبتعبير آخر "خروج الصوت فجأة في صورة أنفجار للهواء عقب احتباسه عند المخرج ، كما في نطق الباء ، والتاء ، الدال ... " (مالمبرج)

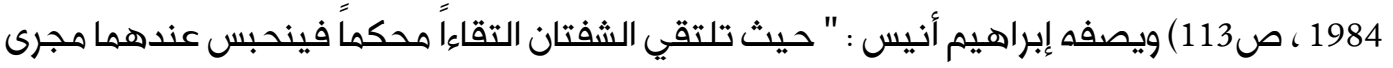
النفس المندفع من الرئتين لحظة من الزمن بعدها تنفصل الشفتان انفصالاً فجائيا، يحدث النفس فـ الهنحبس صوتاً انفجارياً، وهو ما نرمز اليه في الكتابة بحرف الباء ، فهذا النوع من الأصوات الانفجارية

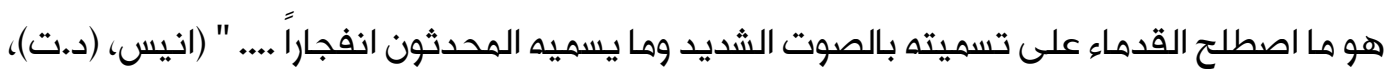
ص24، 25) واشار ايوب بأنهُ الانحباس الهنفجر.

الأصوات الرخوة: "وهو إنْ شئت اجريت الصوت فيه الهاء - الحاء - الغين - الخاء - الشين - الصاد الضاد - الزاي - السين - الظاء - الثاء - الذال - الفاء ..." (سيبويه، 1988، الجزء الرابع ، ص 435)

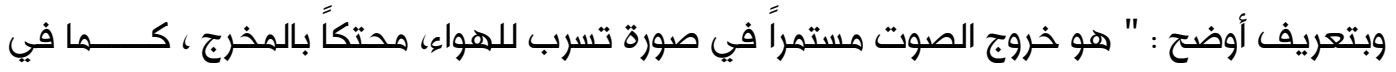
نطق الثاء والحاء والزاي " (مالمبرج ، 1984، ص113) والذي وصفه ايوب (1968) بالانطلاق ، " وهو عدم

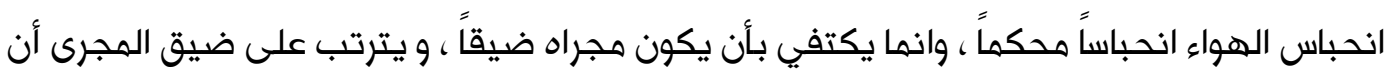
النفس في اثناء مروره بمخرج الصوت يحدث نوعاً من الصفير أو الحفيف تختلف نسبته تبعاً لنسبة ضيق المجرى .... " (انيس، د. ت، ص25) فالشدة والرخاوة إذن عبارة عن خروج الصوت مع الهواء ولكنّ منّ الذي يغير صفته انفجار الصوت بصورة مفاجأة او تسريبيه مع الهواء واحتكاك عند المخرج. 
"تتنوع اشكال اعتراض اعضاء آلة النطق مجرى النفس فتتنوع تبعاً لذلك الاصوات الناتجة عن تلك الاشكال .... ولاحظ علماء الاصوات قدماء ومحدثين ، وجود مجموعة من الاصوات لا تندرج في الاصوات الشديدة ولا الرخوة ، لطبيعة شكل اعتراض الذفس لها وقد سهي علماء العربية والتجويد هذه المجموعة من الأصوات بالمتوسطة أو البينية " (الحمد، 2004، ص 111، 112) ويصفه البعض بأنه "خروج الصوت دون انفجار ، او احتكاك عند المخرج ، وهي حالة أصوات أربعة هي : اللام ، والنون ،

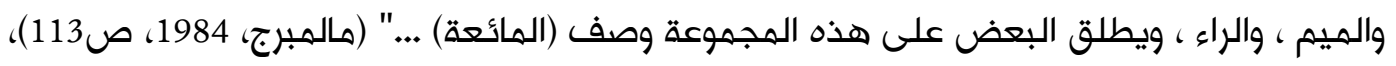
واشار إبراهيم أنيس في كتابه الاصوات اللغوية الى ان تسهيتها بالمتوسطة لا تعني أكثر من أنها تخالف النوعين السابقين ، أي أنها ليست بشديدة ولا رخوة ، وعدَّ الدكتور غانم قدوري أنّ تميز هذهِ

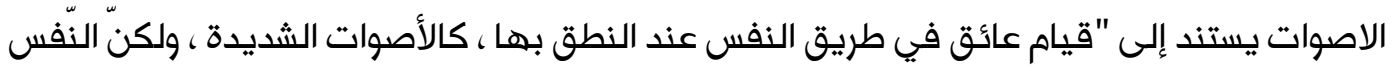

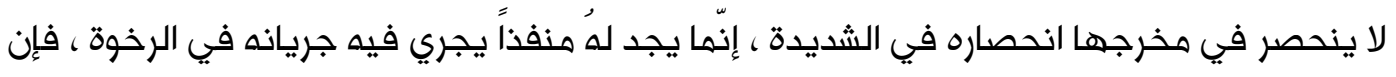
إخراج الأصوات الثلاثة ( و ي أ ر) من الأصوات المتوسطة يكون أرجح من ضمها إليها ، لما تتميز بي

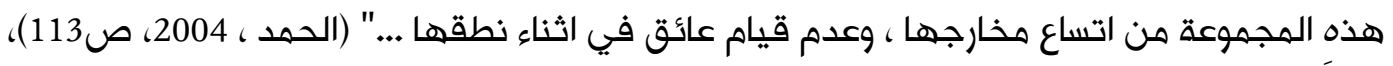
وهذا الرأي اقرب الى الصورة الادق لتكوين هذه الحروف وصفاتها .

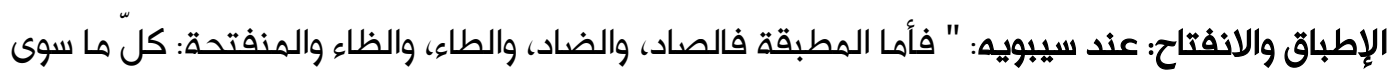
ذلك من الحروف، لأنك لا تطبق لشيء منهن لسانك، ترفعهد الى الحنك الاعلى. وهذه الحروف الأربعة إذا ما وضعت لسانك في موضعهن انطبق لسانك من مواضعهن إلى ما حاذى الحنك الأعلى من اللسان ترفعه الى الحنك الأعلى، فإذا وضعت لسانك فالصوت محصور فيما بين

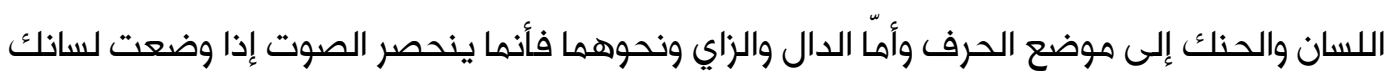
موضعهن. فهذه الأربعة لها موضعان من اللسان، وقد بين ذلك بحصر الصوت، ولولا الاطباق لصارت الطاء دالا، والصادُ سيناً، والظاءُ ذالاً، ولخرجت الضادُ من الكلام، لأنه ليس شيء من موضعها غيرها ..." (سيبويه،

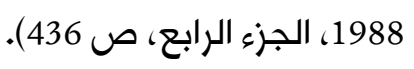
وعلق د. غانم قدوري: " هذا الوصف لهذه الاصوات في كلام سيبويه مبني على ما ينطبق في زمانه

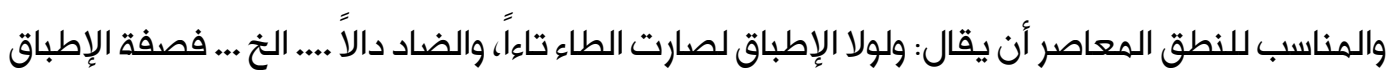
صنعة مميزة للأصوات المشتركة في المخرج" (الحمد، 2004، ص 116). ومما تقدم من وصف هذه الحروف فهي مشتركة بالمخرج مختلفة بالصفة أي اللسان العربي يولّد لنّا حروفاً تختلف في صداها الصوتي باختلاف دقيق في حصر الصوت مما يولد صفات تختلف بين حرف وآخر.. 
"هي مجموعة الصفات التي لاضد لها، ومعنى التحسين في هذه الصفات أنّها تعطي الصوت جرسه الخاص به، من غير أن يكون لها سمة التفريق بين الأصوات، فهي محسنة للأصوات التي تتصف بها

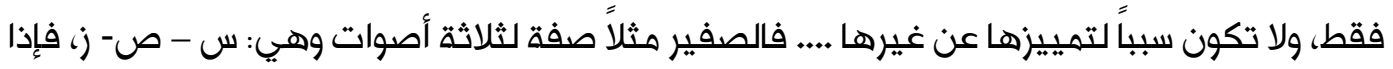
حاولنا سلب هذه منها فإن ذلك إن أمكن تحققه - لا يؤدي الى انتاج اصوات تقابل تلك الاصوات الثلاثة بل يؤدي الى اختلال الصوت وربها زواله. والصفات المحسنة ثماني صفات وهي: القلقة،

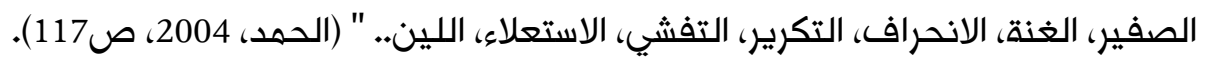

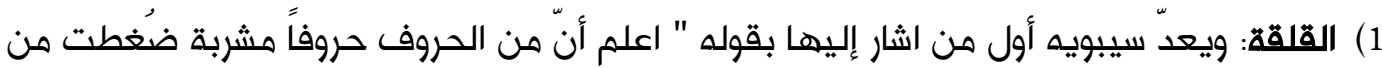
مواضعها ، فإذا وقفت خرج معها من الفم صُويتاً ونبا اللسان عن موضعه ، وهي حروف القلقة،

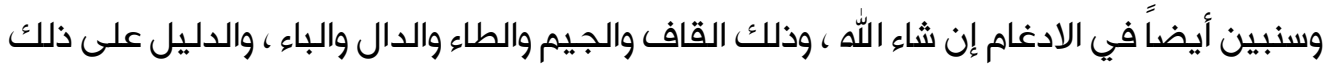
أنك تقول: الخذق فلا تستطيع أن تقف الا مع الصوت لشدة ضغط الحرف وبعض العرب اشذُ

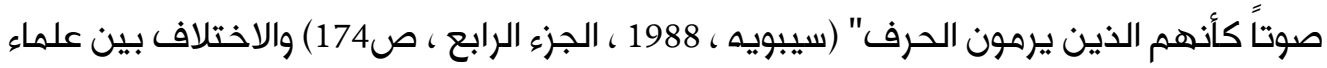

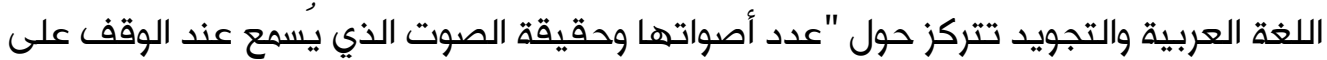
حروفها، وهل تختص بالوقف أو تحصل أيضاً في درج الكلام ... ويذهب الجمهور إنها خمسة مجموعة في (قطب جد) ... أما صوت القلقة الذي يُسمع عند الوقوف على هذه الحروف فهو يتكون نتيجة انفتاح في مخرج الصوت الشديد ، وهو مكملاً للصوت" (الحمد، 2004، ص ص 119، 120 ) ووصفه سيبويه بالصويت (سيبويه ، 1988 ، الجزء الرابع ، صائ174)، والظاهر لي أن هناك أنّهُ لا يبلغ مقداره أن يمثل حرفاً كاملاً كما ذهب إليه اليه العلماء وهو الصحيح ... 2) الصفير: وهي حروف اندى في السمع وهُن حروف صفير وتكون شديدة ورخوة (مالمبرج، "وكون الصوت شديد في السهع نتيجة الاحتكاك الشديد في المخرج ، وهو وصف صادق على ثلاث صوامت هي : السين - الزاي - الصاد" (الحمد ، 2004 ، ص123)،ثم اشار احمد انها سميت هذه المجموعة بأصوات الصفير تشبيهاً لصوتها بالصفير، اذن هذه الاصوات لها من شدة الاحتكاك وضوحاً بالسهع كالصفير ووضحه في ذهن السامع • 3) الغُنةُة: الغنة تحدث "عند النطق بالسواكن الأنفية يلتقي جزء من أجزاء اللسان بسقف الحنك بحيث

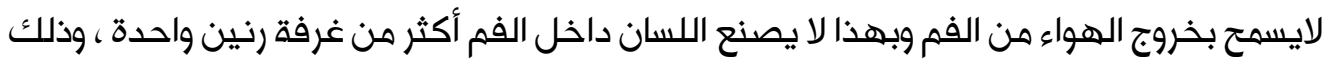
على العكس من الحركات التي تقسم أعلى نقطة في اللسان عند نطقها منطقة الفم أي غرفتي رنين أمامية وخلفية ، ولكن هذا لا يعني وجود غرفة رنين واحدة عند النطق بالسواكن الأنفية ، إذ إن أنَّ هناك إلى جانب غرفة الرنين الفموية غرف رنين أخرى أنفية" (ايوب ، 1968 ، ص191) وقال فيها محمود السعران : " هو أن يحبس الهواء حبساً تاماً في موضع من الفم ولكن يخفض الحنك اللين فيتمكن الهواء من النفاذ عن طريق الأنف"(السعران، د. ـ ت، ص 168) [21] وعدّ د. غانم 
قدوري أنّ العلماء قد وهموا في اشتراط وجود الغنة في النون والميم، أن يكونا ساكنين غير

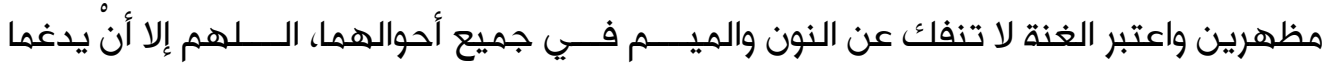

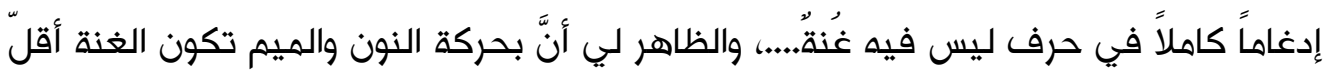
ولكنها أكثر وضوحاً في حالة السكون.

4) الانحراف: " وضع عقبة في وسط الهجرى الهوائي مع ترك منفذ عن طريق أحد جانبي العقبة ، أو عن جانبيها ، ومن هنا كانت تسميتها بالمنحرفة (أو الجانبية) ومن امثلتها اللام في العربية" (السعران ، د .ت ، ص169)، ويعتبر سيبويه أول من استخدم هذا المصطلح في وصف اللام ، وعرفه "حرف شديد جرى فيه الصوت لانحراف اللسان مع الصوت ، ولم يعترض على الصوت كاعتراض الحروف الشديدة وهو اللام وأن شئت مددت فيها الصوت ، وليس كالرِّخوة ، لأن طرف اللسان لا يتجافى عن موضعه، وليس يخرج الصوت من موضع اللام ولكن من ناحيتي مستدق اللسان فويق ذلك" (سيبويه ، 1988 ، الجزء الرابع ، ص435)، إذن انحراف امتداد الصوت في تجويف الفم الى ناحيتي مستدق اللسان فويق ذلك ليكتسب هذا الصوت صفه (الانحراف) تمثيلاً لدافع المخرج الصوتي له ، وهذا جعل بعض المحدثين يستحدثون مصطلح (الجانبي) في وصف اللام (السعران ، د. ت ، ص 171)، والظاهر لي أنّ تسمية اللام أو وصفه (بالانحراف) أكثر ايحاءً وتمييزاً لهذا الصوت. 5) التكرير:" وهو حرف شديد يجري فيه الصوت لتكريره وانحرافه الى اللام ، فتجافى للصوت كالرخوة ، ولو لم يكرر لم يجر الصوت فيه ، وهو الراء" (سيبويه ، 1988 ، الجزء الرابع ، ص435)، ومما تقدم من تعريف يجعل سيبويه التكرار شرط في حدوث الراء "فتتابع طرقات طرف اللسان تتابعاً سريعاً ويوضع طرف اللسان سمحاً في موضعه المناسب ، ويذبذبه العمود الهوائي" (السعران ، د. ت، 6) التفشي: " وهو أن يشغل اللسان أثناء النطق بالصوت مساحة أكبر، ما بين الغار واللثة وهو وصف

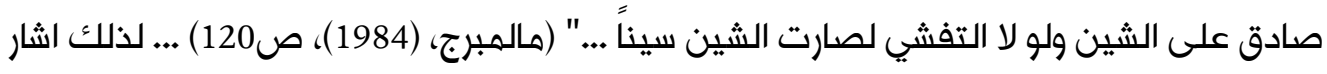
الحمد انهم جعلوا ذلك تعليلاً لعدم إدغام الشين في غيرها. 7) الاستعلاء: ارتفاع اللسان بجزئه الخلفي نحو اللهاة وهي القاف، الغين، الخاء ويشير المرعشي انها الى جهة الحنك الاعلى [22] ان ارتفاع اللسان الى جهة الحنك الاعلى وهي صفة لبعض الاصوات الخلفية ويعتبر بعض العلماء أنّ صفة الاستعلاء ادخل في الصفات المحسنة من مصطلح الاستفال أو المستفلة).

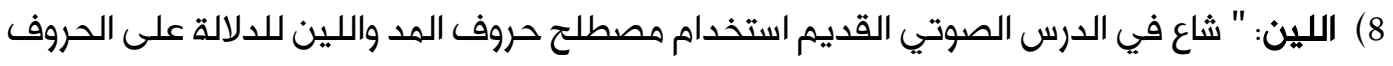
الثلاثة: الألف والواو والياء، وهو عبارة عن اتساع المخرج الصوتي أكثر من غيرها من الأصوات 
الرخوة، وهي منزلة وسطى بين الأصوات الرخوة والأصوات الذائبة" (الحمد، 2004 ،132) إذن هو امتداد للصوت دون عارض يعرض له فيثنيه عن امتداده.

وهناك اختلاف في علم الصوت الحديث بين مصطلح الصوت والحرف وقد تعرفنا على الصوت في

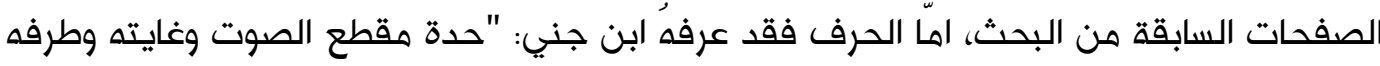

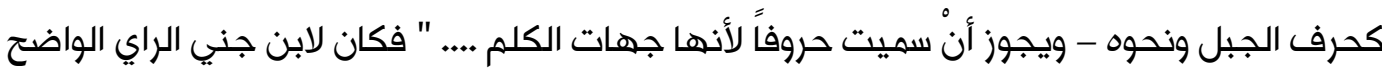

$$
\text { في تعريف الحرف. }
$$

ويرجح ان سيبويه لم يفرق بين الحرف والصوت في باب الادغام بشكل مفصل، ولسنا في صدد التفريق بين الصوت والحرف لأنه باب واسع ولا يسمح له منهجية البحث.

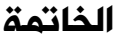

\section{أهم النتائج التي توصلتُ اليها}

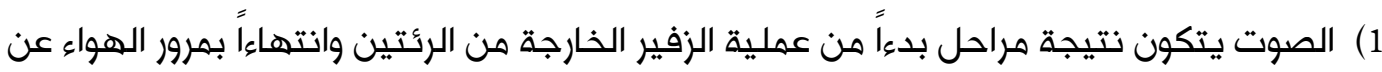
طريق الشفتين وليس كما كان الاعتقاد ان الاوتار الصوتية في الحنجرة هي الاساس في تكون

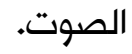
2) إن نشأة اللغة عبارة عن (علم وضعهُ الله تعالى على لسان آدم) ولم تنشأعبر العصور وبالتالي سحر

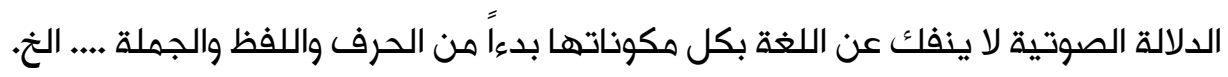
3) الاعجاز الصوتي يتمثل في القرآن الكريم خصوصاً وفي اللغة عموهاً اذا توفرت أساليب البيان وغيرها مثال (نهج البلاغة والمعلقات وغيرها) ، والراجح أن اللغات كلها بدأت بأعلى مستوياتها الصوتية والدلالية ثم فقدت هذا المستوى بمرور الزمن.

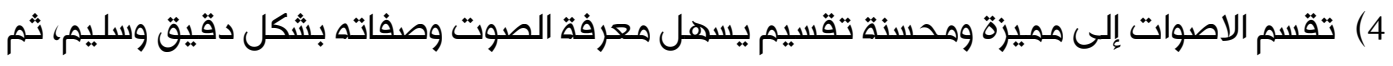

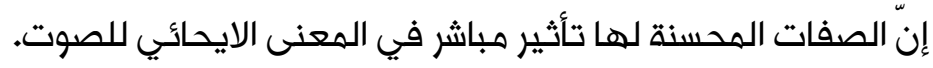

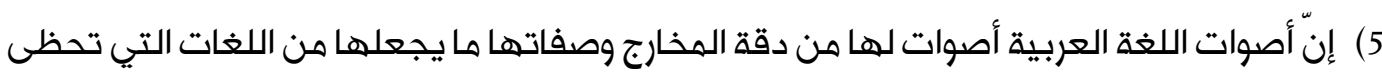
بمستوى عالٍ من الابداع الصوتي على اللسان العربي... مثال : حرف الطاء والدال ... والظاء والذال.. كما وصفها علماء الصوت تشترك في المخارج وتغيرت في الصدى الصوتي بسبب تغير بسيط

$$
\text { في هجرى الهواء المحبوس. }
$$

6) اثبات الدلالة الصوتية للحرف نفسه جهوداً قد تصدى لها علماء اللغة القدهاء، وان كانت في الهاء الاغلب بين طيات كتبهم ولكنها وقفه علمية دقيقة وواضحة مثال نسبة القوة للقاف ونسبة الضعف للخاء عند ابن جني (ت 392هـ) وغيره من اعلام اللغة فهي لوحة فنية علمية لإيصال فكرة الدلالة الصوتية للحرف نفسه.

الساعدي، امنة جبار علوان. (2019). علم الصوت اللغوي. Journal Port Science Research، 2(3) ، 479-463. 
7) عند مقارنة صفات أصوات الالفاظ مع معنى اللفظ المعجمي نجد تقارباً لا يخفى بين الدلالة الصوتية والدلالة المعجمية، فمن المعاني التي نسبت للهاء مثلاً الرقة والسعة خاصة اذا انتهت بها الكملة ونجد أغلب المعاني المعجمية قد تضمنها المعنى الصوتي المبتغى اليه كلفظة

$$
\text { (هداية، ورحمه وغيرها) }
$$

\section{التوصيات}

1) الأخذ بالدلالة الصوتية كجزء لا يتجزأ من دراسة علم الصوت اللغوي. 2) الاهتمام بعلم الصوت، واعتباره من العلوم الأساس في علم اللغة العربية. 3) تشجيع البحوث العلمية في مجال الصوت لمواكبة علماء الغرب في هذا المجال العلمي ....، وإكمال نهج علماؤنا القدماء الذين قدموا حقائق علمية كانت أساس في هذا العلم. 4) إن معرفة معنى الصوت وربطه بالنطق الصحيح يساعد في فهم معنى الكلام وإيضاحه عند المتلقي.

5) الاهتمام بدراسة نشأة اللغة ومعرفة حقيقتها تساعد على فهم ومعرفة اللغة بشكل سليم. 6) وضع مناهج صوتية لغوية في المؤسسات التربوية لتنشأ جيل واعٍ في فهم اللغة من حيث الصوت. 7) إرساخ حقيقة علمية بأن علم الصوت يرتبط بالقران الكريم ارتباطا وثيقاً ومعرفته تساعد على معرفة أسرار القران الكريم وبلاغته.

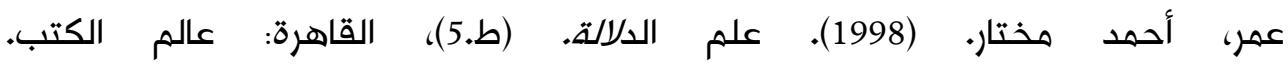
http: / / daulatulkitab.blogspot.com/2017/09/pdf_74.html [2] الخليل بن أحمد الفراهيدي. (2003). العين. (عبد الحميد الهنداوي. تحقيق ودراسة) (ط1). دار https: / / ar.m.wikosource.org الكتب العلمية. [3] أبي الفتح عثمان بن جني. (1952). الخصائص. (محمد علي النجار، تحقيق). دار الكتب المصرية. www.ar.islamic-sources.com [4] العلايلي. (1985). تهذيب المقدمة اللغوية. (أسعد أحمد علي) دمشق: دار السؤال. www.bookleaks.com

[5] عباس ، حسن (1998) ، خصائص الحروف العربية ومعانيها. منشورات إتحاد كتاب العرب.

https://khatabaa.com

[6] فارس الشدياق. (د.ت). الساق على الساق فيما هو الفارياق. (همفري ديفيز). المكتبة العربية. http:/ / www.libraryofarabicliterature.org Alsaedy, A. (2019). PHonetcs. Journal Port Science Research, 2(3), 463-479. doi.org/10.36371/port.2018.02.3.7 
j. port. sci. res.
ISSN: $2616-74$

[7] الحجازي، محمد فهمي. (د.ت). المدخل إلى علم اللغة. القاهرة: دار قباء. http:/ / Daulatulkitab.blogspot.com

[8] [بد الكريم، مجاهد. (1986) دراسات في اللغة. دار الشؤون الثقافية. / faylasof.com: [9] بافو. م وسرفاتي. (2012). النظريات اللسانية الكبرى من النمو المقارن الى الذرائعية. (محمد http:/ / lissanrab.blogspot.com الراضي- مترجم) ط.1. بيروت: مركز دراسات الوحدة العربية. [10] فردينان دي سويسر. (1985). علم اللغة العام. (يوئيل يوسف عزيز: مترجم) (ط.3) دار آفاق عربية. www.mohamedrabea.net

[11] الطبطبائي، محمد حسين. (1417). الميزان في تفسير القرآن. لبنان: بيروت: مؤسسة الأعلى للمطبوعات.

[12] جمال الدين أبي الفضل محمد بن مكرم ابن منظور الانصاري الأفريقي المصري. (2009) لسان العرب. (عامر أحمد حيدر: حققه) (وعبد الهنعم جليل إبراهيم راجعه) بيروت دار الكتب العلمية. http://waqfeya.com

[13] أبي الفتح عثمان بن جني. (1993). سر صناعة الأعراب. (حسن هنداوي: دراسة وتحقيق) (ط2) دمشق: دار القلم.

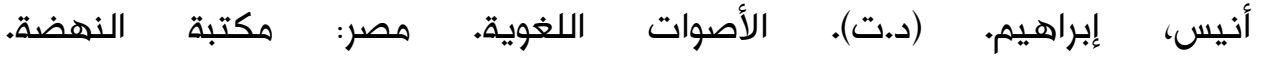
http:/ / daulatulkitab.blogspot.com [15] مالمبرج • ب. (1984). علم الأصوات. (عبد الصبور شاهين: مترجم ودارس). مصر. مكتبة الشباب. [16] مالمبرج. ب. (1994). الصوتيات. (محمد حلمي خليل مترجم)، عين للدراسات والبحوث الإنسانية والاجتماعية. http://books.google.com

الحمد، غانم قدوري. (2004). المدخل الى علم أصوات العربية. (ط1). الاردن: دار عمار. http://www.scribd.com أبي بشر عمرو بن عثمان قنبر سيبويبه. (1988). الكتاب. (عبد السلام محمد هارون: تحقيق وشرح).

https: / / www.ahlalhdeeth.com [19] الصيغ، عبد العزيز. (1998). المصطلح الصوتي. دار الفكر. Www.m-a-arabia.com [20] أيوب، عبد الرحمن. (1968). أصوات اللغة. مطبعة الكيلاني (ط.2). acoustics.blogspot.com /2015/05/blog-post_53.html 
j. port. sci. res.

(Online)

SN: 2616-6232 (Print)

INTERNATIONAL IDENTIFIER FOR SERIALS

ournal port Science Research

Available online www.jport.co

Q.0.0.0.0.0:0:0:0 Volume:2, No:3

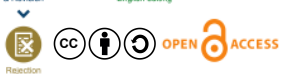

[21] السعران ، محمود. (د.ت). علم اللغة مقدهة للقارئ العربي. بيروت: دار النهضة العربية. http://phonetics-acoustics.

[22] محمد بن أبي بكر المرعشي الملقب بساجقلي زاده (2008). جهد المقل. (سالم قدوري حمد -

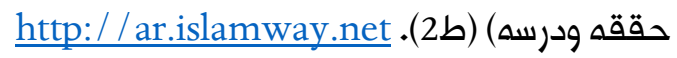

